Bull. Mater. Sci., Vol. 5, No. 5, December 1983, pp.449-452.(C) Printed in India.

\title{
Microhardness and interatomic binding in some cubic crystals
}

\author{
K KISHAN RAO and D B SIRDESHMUKH \\ Physics Department, Kakatiya University, Warangal 506 009, India
}

MS received 7 October 1982

\begin{abstract}
Vicker's microhardness measurements have been carried out on single crystals of $\mathrm{CaF}_{2}, \mathrm{SrF}_{2}, \mathrm{BaF}_{2}, \mathrm{CdF}_{2}, \mathrm{PbF}_{2}, \mathrm{FuF}_{2}, \mathrm{ThO}_{2}, \mathrm{NaClO}_{3}, \mathrm{NaBrO}_{3}, \mathrm{Bi}_{4}\left(\mathrm{GeO}_{4}\right)_{3}$, $\mathrm{Bi}_{4}\left(\mathrm{SiO}_{4}\right)_{3}, \mathrm{Bi}_{12} \mathrm{GeO}_{20}$ and $\mathrm{Bi}_{12} \mathrm{SiO}_{20}$. The hardness values are discussed vis-a-vis the interatomic binding in these crystals. While most of the fluorite-type crystals are highly ionic, covalency is indicated in the bismuth compounds studied.
\end{abstract}

Keywords. Cubic crystals; microhardness; fluorite-type crystals; interatomic binding.

\section{Introduction}

Hardness is an important solid state property. Hardness tests are commonly carried out to determine the mechanical strength of materials and it correlates with other mechanical properties like elastic constants (Wooster 1953) and yield stress (Westbrook 1958).

Stillwel (1938) defined hardness as resistance against lattice destruction whereas Ashby (1951) defined it as the resistance offered by a solid to permanent deformation. It is now accepted that hardness is a measure of the resistance that a lattice offers to the motion of dislocations.

The chemical forces in a crystal resist the motion of dislocations as it involves the displacement of atoms. This resistance is the intrinsic hardness of a crystal. Gerk (1977) calls the hardness of a high purity, good quality, well-annealed crystal 'the minimum hardness'. Hardness values obtained from such crystals can thus be correlated with the strength of interatomic binding in these crystals. Plendl and Gielisse (1962) have correlated the hardness of several crystals with their lattice energy. Berzina et al (1965) found that the hardness values correlate with surface energy values. Powarjonnych (1963) and Julg (1978) attempted to draw quantitative information about the bond strength from hardness values. Recently, Chin (1975) suggested that the ratio of microhardness to the shear elastic constant has typical values for different bonding types. Thus, this ratio (hereafter referred to as the Chin parameter) is about 0.1 for covalent solids and 0.05 for ionic solids (Chin et al 1978).

In this paper, the results of measurement of microhardness of thirteen cubic crystals are reported; in several cases, this is the first measurement. The results are discussed vis-a-vis the interatomic binding. 


\section{Experimental}

Microhardness was measured at room temperature using a Leitz Weitzlar hardness tester fitted with a Vicker's diamond pyramidal indenter, and was calculated using the equation

$$
H=1.854 P / d^{2}
$$

where $H$ is the microhardness $\left(\mathrm{kg} / \mathrm{mm}^{2}\right), P$ is the load (grams) and $d$ is the length (in microns) of the diagonal of the indentation mark.

Microhardness values show a load dependence at low loads up to $25 \mathrm{~g}$ above which they become load-independent (Mott 1956; Sirdeshmukh and Shah 1965). Keeping this in view, the measurements were carried out at loads of $50 \mathrm{~g}$ or more. Depending upon the nature of the sample, different loads were chosen for different samples so that the indentation marks were of measurable dimensions. In every case, at least five measurements were made. The final value is the average of these and is accurate to $\pm 2 \mathrm{~kg} / \mathrm{mm}^{2}$.

The crystals of $\mathrm{CaF}_{2}, \mathrm{BaF}_{2}, \mathrm{SrF}_{2}, \mathrm{CdF}_{2}$ and $\mathrm{PbF}_{2}$ were from M/s Optovac, the $\mathrm{EuF}_{2}$ crystal was obtained from Dr $\mathrm{H} \mathrm{V}$ Lauer of Purdue University and the $\mathrm{ThO}_{2}$ crystal was a gift from Prof.K Vedam of the Pennsylvania State University. The $\mathrm{Bi}_{4}\left(\mathrm{GeO}_{4}\right)_{3}$ and $\mathrm{Bi}_{4}\left(\mathrm{SiO}_{4}\right)_{3}$ crystals were grown and cut by $\mathrm{Dr} \mathrm{W}$ Rehwald of RCA Laboratories. The $\mathrm{Bi}_{12} \mathrm{GeO}_{20}$ and $\mathrm{Bi}_{12} \mathrm{SiO}_{20}$ crystals were presented by Dr T M Bruton of Mullard Laboratories. The $\mathrm{NaClO}_{3}$ and $\mathrm{NaBrO}_{3}$ crystals were grown from aqueous solutions employing standard procedures. All the crystals were annealed at appropriate temperatures before the measurements.

Table 1. Values of microhardness $(H)$, shear constant $\left(C_{44}\right)$ and Chin parameter $\left(H / C_{44}\right)$ for some cubic crystals.

\begin{tabular}{lcccc}
\hline Crystal & $\begin{array}{c}\text { Face on which } \\
\text { hardness was } \\
\text { measured }\end{array}$ & $\begin{array}{c}H \\
\left(\mathrm{~kg} / \mathrm{mm}^{2}\right)\end{array}$ & $\begin{array}{c}C_{44} \\
\left(\mathrm{~kg} / \mathrm{mm}^{2}\right)\end{array}$ & $H / C_{44}$ \\
\hline & & & & \\
$\mathrm{CaF}_{2}$ & $(111)$ & 185 & $3450^{a}$ & 0.05 \\
$\mathrm{SrF}_{2}$ & $(111)$ & 163 & $3100^{a}$ & 0.05 \\
$\mathrm{BaF}_{2}$ & $(111)$ & 149 & $2400^{a}$ & 0.06 \\
$\mathrm{PbF}_{2}$ & $(111)$ & 133 & $2500^{a}$ & 0.05 \\
$\mathrm{CdF}_{2}$ & $(111)$ & 153 & $2100^{b}$ & 0.07 \\
$\mathrm{EuF}_{2}$ & $(111)$ & 264 & $3050^{c}$ & 0.09 \\
$\mathrm{ThO}_{2}$ & $(111)$ & 750 & $8100^{a}$ & 0.09 \\
$\mathrm{NaClO}_{3}$ & $(100)$ & 107 & $1179^{d}$ & 0.09 \\
$\mathrm{NaBrO}_{3}$ & $(100)$ & 136 & $1536^{d}$ & 0.09 \\
$\mathrm{Bi}_{4}\left(\mathrm{GeO}_{4}\right)_{3}$ & $(100)$ & 561 & $5280^{e}$ & 0.11 \\
$\mathrm{Bi}_{4}\left(\mathrm{SiO}_{4}\right)_{3}$ & $(100)$ & 593 & $4440^{e}$ & 0.12 \\
$\mathrm{Bi}_{12} \mathrm{GeO}_{20}$ (BGO) & $(100)$ & 372 & $2600^{f}$ & 0.14 \\
$\mathrm{Bi}_{12} \mathrm{SiO}_{20}(\mathrm{BSO})$ & $(100)$ & 473 & & \\
\hline
\end{tabular}

${ }^{a}$ Chung and Buessem (1968); ${ }^{b}$ Alterovitz and Gerlich (1970); ${ }^{c}$ Lauer et al (1971);

$d$ Haussuhl (1964); ${ }^{e}$ Rehwald and Widmer (1973); $f$ Slobodnik and Sethares (1972). 


\section{Results and discussion}

The microhardness values for thirteen cubic crystals are given in table 1 . The value of $185 \mathrm{~kg} / \mathrm{mm}^{2}$ obtained for $\mathrm{CaF}_{2}$ agrees well with the value $175 \mathrm{~kg} / \mathrm{mm}^{2}$ quoted by Mott (1956). For $\mathrm{NaClO}_{3}$ and $\mathrm{NaBrO}_{3}$, Haussuhl (1964) reported values 123 $\mathrm{kg} / \mathrm{mm}^{2}$ and $195 \mathrm{~kg} / \mathrm{mm}^{2}$ respectively. The present values are also of the same order but smaller in both cases. In the case of the remaining crystals, this appears to be the first measurement of Vicker's hardness.

It is now established that the hardness of sodium bromate is more than that of sodium chlorate. In this respect these two crystals differ from the corresponding halides where the hardness of sodium bromide is less than that of a sodium chloride (Berzina et al 1965). Radha and Gopal (1968) pointed out that the difference in the behaviour of sodium chlorate and sodium bromate on the one hand and sodium chloride and sodium bromide on the other, is manifested in several other physical properties like elastic constants, thermal expansion etc. They have suggested that this difference arises out of the fact that the $\mathrm{NaCl}$ distance in sodium chlorate is larger than the $\mathrm{NaBr}$ distance in sodium bromate whereas in the sodium halides the $\mathrm{NaCl}$ distance is shorter than the $\mathrm{NaBr}$ distance. This may explain the difference between the relative values of the hardness of the sodium halates and the sodium halides.

In $\mathrm{Bi}_{4}\left(\mathrm{GeO}_{4}\right)_{3}$ and $\mathrm{Bi}_{4}\left(\mathrm{SiO}_{4}\right)_{3}$, the hardness of the orthosilicate is more than that of orthogermanate. This is consistent with the conclusions drawn by Rao et al (1981) from the values of the elastic constants and Debye temperatures. Again, in the case of $\mathrm{Bi}_{12} \mathrm{GeO}_{20}$ (BGO) and $\mathrm{Bi}_{12} \mathrm{SiO}_{20}$ (BSO), the hardness of BSO is much greater than that of BGO indicating the stronger binding in the former. Structural data (Abrahams et al 1979) on these crystals show that most of the interatomic distances in BSO are shorter than the corresponding distances in BGO. Thus, it appears reasonable that the hardness of BSO should be more than that of BGO.

The hardness values are now examined in terms of the Chin parameter. As mentioned in $\S 1$, Chin (1975) has pointed out that the ratio $H / C_{44}$ (where $C_{44}$ is the shear elastic constant) is characteristic of the bonding in cubic solids. This parameter has a value of about 0.1 for covalent solids and a value of 0.04-0.06 for ionic solids (Chin et al 1978). The $C_{44}$ values and those of the $C$ hin parameter $\left(H / C_{44}\right)$ are given in table 1 . Some interesting features are observed. The Chin parameter value for $\mathrm{CaF}_{2}, \mathrm{SrF}_{2}, \mathrm{BaF}_{2}, \mathrm{CdF}_{2}$ and $\mathrm{PbF}_{2}$ is about 0.06 showing that these are essentially ionic like the alkali halides. This conclusion is consistent with that drawn from other properties like lattice energies (Ladd and Lee 1964), and thermal expansion (Sirdeshmukh and Rao 1972). On the other hand, the Chin parameter value is about 0.1 for $\mathrm{BGO}, \mathrm{Bi}_{4}\left(\mathrm{GeO}_{4}\right)_{3}$ and $\mathrm{Bi}_{4}\left(\mathrm{SiO}_{4}\right)_{3}$ indicating the existence of a covalent component in the binding in these crystals. In $\mathrm{EuF}_{2}, \mathrm{ThO}_{2}$, $\mathrm{NaClO}_{3}$ and $\mathrm{NaBrO}_{3}$, the Chin parameter has a value 0.09 which suggests a partial ionic character.

\section{References}

Abrahams S C, Bernstein J L and Svensson C 1979 J. Chem. Phys. 71788

Alterovitz S and Gerlich D 1970 Phys. Rev. B1 4136 
Ashby N A 1951 N.Z. Eng. 633

Berzina I G, Berman I B and Savintsev P A 1965 Sov. Phys. Crystallogr. 9483

Chin G Y 1975 in Deformations in ceramic moterials (New York: Plenum Press)

Chin G Y, Wernick J H, Geballe T H, Mohajan S and Nakahara S 1978 Appl. Phys. Lett. 33103

Chung D H and Buessem W R 1968 Anisotropy in single crystal refractory compounds (New York: Plenum Press)

Gerk A P 1977 J. Mater. Sci. 12735

Haussuhl S 1964 Phys. Kondens. Mater. 3139

Julg A 1978 Phys. Chem. Miner. 345

Ladd M F C and Lee W H 1964 Prog. Solid State Chem. 137

Lauer Jr H V, Solberg K A, Kuhner D A and Bron W E 1971 Phys. Lett. A35 219

Mott B W 1956 Microindentation hardness testing (London: Butterworths)

Plendl J N and Gielisse P J 1962 Phys. Rev. 125828

Powarjonnych A S 1963 Quoted by Plendl J N and Gielisse P J Z. Krystallogr. 118404

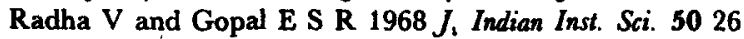

Rao B K, Subhadra K G and Sirdeshmukh D B 1981 Indian J. Pure Appl. Phys. 1987

Rehwald W and Widmer R $1973 \mathrm{~J}$. Phys. Chem. Solids 342269

Sirdeshmukh D B and Shah B S 1965 J. Maharaja Sayajirao Univ. Baroda 1449

Sirdeshmukh D B and Rao B K 1972 J. Chem. Phys. 57577

Slobodnik Jr A J and Sethares J C 1972 J. Appl. Phys. 43239

Stillwel C W 1938 Cyystal chemistry (New York: McGraw Hill)

Westbrook J H 1958 Flow in rock salt structures (Report 58-RL-2033 of the G.E. Research Laboratory)

Wooster W A 1953 Rep. Prog. Phys. 1662 